\title{
EVOLUTION OF A MARS AIRPLANE CONCEPT FOR THE ARES MARS SCOUT MISSION
}

\author{
Mark D. Guynn* and Mark A. Croom ${ }^{\dagger}$, NASA Langley Research Center, Hampton, VA 23681 \\ Stephen C. Smith ${ }^{\star}$, NASA Ames Research Center, Moffett Field, CA 94035 \\ Robert W. Parks ${ }^{\S}$, Aurora Flight Sciences, Manassas, VA 20110 \\ Paul A. Gelhausen", AVID LLC, Yorktown, VA 23692
}

\begin{abstract}
ARES (Aerial Regional-scale Environmental Survey of Mars) is a proposed Mars Scout mission using an airplane to provide high-value science measurements in the areas of atmospheric chemistry, surface geology and mineralogy, and crustal magnetism. The use of an airplane for robotic exploration of Mars has been studied for over 25 years. There are, however, significant challenges associated with getting an airplane to Mars and flying through the thin, carbon dioxide Martian atmosphere. The traditional wisdom for aircraft design does not always apply for this type of vehicle and geometric, aerodynamic, and mission constraints result in a limited feasible design space. The ARES airplane design is the result of a concept exploration and evolution involving a number of trade studies, downselects, and design refinements. Industry, university, and NASA partners initially proposed a number of different concepts, drawing heavily on past Mars airplane design experience. Concept downselects were conducted with qualitative evaluation and highlevel analyses, focused on the most important parameters for the ARES mission. Following a successful high altitude test flight of the basic configuration, additional design refinement led to the current design. The resulting Mars airplane concept enables the high-value science objectives of the ARES mission to be accomplished while also fulfilling the desire for a simple, low-risk design.
\end{abstract}

\section{INTRODUCTION}

The vision of winged vehicles flying through the Martian atmosphere has existed for at least 50 years. In Wernher von Braun's book The Mars Project, first published in the early 1950's, human explorers of Mars are transferred from orbit to the surface using landing gliders. ${ }^{1}$ For over 25 years serious consideration has been given to the use of an unmanned Mars airplane as a science platform. The idea of performing scientific observations on Mars using an airplane has persisted

\footnotetext{
* Aerospace Engineer; Senior Member AIAA.

${ }^{\dagger}$ ARES Airplane Chief Engineer; Member AIAA.

* Research Engineer; Associate Fellow AIAA.

$\S$ Senior Aircraft Designer; Member AIAA.

" Chief Technology Officer; Senior Member AIAA.
}

because of the clear advantages associated with an airborne platform. Just like on Earth, airborne observations would complement ground-based and space-based observations, permitting higher resolution than possible with space-based platforms and greater coverage than possible with ground-based platforms. An airplane offers an additional advantage over other airborne platforms (e.g., balloons) in that it can be maneuvered to specific locations of interest. There are several technical challenges associated with a Mars airplane, however.

The first and foremost consideration in Mars airplane design is the nature of the Martian atmosphere. Atmospheric density near the Martian surface is roughly equivalent to an altitude of 100,000 feet on Earth. With such a thin atmosphere, generating enough lift to support the airplane weight is difficult and wing loading has to be small. Fortunately, the airplane weight is only $\sim 38 \%$ of what it would be on Earth due to the lower gravity on Mars. Nevertheless, an emphasis must still be placed on minimizing airframe and system masses in order to achieve the required low wing loading. The flight conditions on Mars are unlike those normally encountered by Earth aircraft. The low atmospheric density leads to a high cruise velocity, but a low flight Reynolds number. Since the speed of sound on Mars is lower than on Earth, transonic aerodynamic effects are encountered at a lower flight speed. Special care must be taken in the aerodynamic design to avoid dramatic losses in lift and/or dramatic increases in drag associated with the low Reynolds number, high Mach number flight conditions. Low atmospheric density also presents problems with generating thrust. For an Earth airplane thrust is usually generated by transferring momentum to freestream air. The lower the atmospheric density, the less mass available for momentum transfer and the less thrust that can be generated for a given size propulsion system. A Mars airplane propeller, for example, would have to be larger than a typical Earth propeller to generate the same amount of thrust. A lack of appreciable amounts of atmospheric oxygen $\left(\mathrm{O}_{2}\right)$ presents another propulsion issue. Most Earth airplanes use air-breathing propulsion systems, relying on $\mathrm{O}_{2}$ from incoming air as an oxidizer to release energy

American Institute of Aeronautics and Astronautics 
stored in the on-board fuel. This approach is not viable in the mainly carbon dioxide $\left(\mathrm{CO}_{2}\right)$ Martian atmosphere. Numerous concepts exist for non-airbreathing propulsion systems. Unfortunately, they generally have much higher fuel consumption and/or additional system mass and complexity compared to conventional airplane propulsion. This makes the efficiency and mass of the rest of the airplane system even more critical.

In addition to the challenge of generating sufficient lift and thrust to fly an airplane through the Martian atmosphere, there are challenges associated with getting the airplane to Mars. The geometric arrangement best suited for efficient, stable atmospheric flight is much different from that best suited for launch and atmospheric entry. Efficient packaging of the aircraft is critical to provide sufficient wing area (lift capability) within the geometric constraints of the launch and entry vehicles. Generally, the airplane must be stowed in a non-flight configuration during the transit to Mars. Once at Mars the airplane must be deployed into its flight configuration. If a mid-air deployment approach is used, not only must the aircraft successfully deploy, but there is also a transition from "falling" to flying that has to be accomplished. This mid-air conversion from the stowed configuration to flight, in which the airplane must take shape, orient itself, and execute a pullout maneuver, is a critical design point. ${ }^{2}$

Mars airplane design involves a number of challenges that are not encountered in the design of Earth airplanes. However, over the decades in which the dream of flying on Mars has endured, numerous studies have investigated options for overcoming these challenges. In addition, there have been important technology advances and successes in the related field of high-altitude Earth airplanes which can be leveraged for a successful Mars airplane design. Following a brief look at Mars airplane design from a historical perspective, this paper describes the evolution of Mars airplane designs for the ARES (Aerial Regional-scale Environmental Survey of Mars) Mars Scout mission. Through a combination of concept exploration and past design experience, a viable Mars airplane, ARES-1, was developed in 2002 for the ARES Step 1 Mars Scout proposal. The ARES mission was one of four Mars Scout proposals selected in December 2002 for continued study. Additional maturation and refinement of the airplane design led to an improved design, ARES-2, which was detailed in the ARES Concept Study Report submitted to the Mars Scout program in May 2003.

\section{HISTORICAL PERSPECTIVE}

In the late 1970's, with funding and direction from the Jet Propulsion Laboratory (JPL), Developmental Sciences, Inc. (DSI) conducted what was probably the most comprehensive early investigation of the feasibility of a Mars airplane. ${ }^{3}$ This investigation grew out of a recognition that the remotely piloted "MiniSniffer" aircraft developed at NASA Dryden for highaltitude Earth atmospheric research could serve as a precursor to a Mars airplane. One of the unique features of the "Mini-Sniffer" concept was a non-airbreathing hydrazine fueled engine developed by James Akkerman. The DSI study investigated a number of airplane and mission design options. The final mission scenario selected was elaborate, involving 3 spacecraft carrying 4 airplanes each. Once at Mars the spacecraft were to be used as communication satellites to provide global communication coverage for the airplanes. The DSI airplane (named "Astroplane" by DSI) had a wingspan of $21 \mathrm{~m}$, wing area of $20 \mathrm{~m}^{2}$, and a nominal mass of $300 \mathrm{~kg}$. A complex folding scheme, which included 6 wing folds, 3 fuselage folds and a folding propeller, was necessary to fit the Astroplane into a $3.8 \mathrm{~m}$ Viking-like aeroshell. The DSI study was terminated in 1978 following a NASA decision to pursue other Mars exploration priorities. Although the concept was not carried forward, the resulting report ${ }^{3}$ documents the challenges of flying on Mars and possible approaches for meeting those challenges.

Since the DSI study there have been several NASA, industry, and university studies of Mars airplane missions. Of particular importance to the ARES project was a recent NASA led effort to develop an airplane mission as part of the Mars Micromission Project. The goal of the Mars Micromission Project was to send a series of small, low-cost spacecraft to Mars. The spacecraft were to be launched as secondary payloads on Ariane 5 commercial launches. This small-scale, low-cost approach to Mars exploration stands in stark contrast to the ambitious and expensive mission envisioned in the DSI Mars airplane study. A relatively short, but intense, Mars airplane concept development effort was initiated in February 1999 by Dan Goldin's (then NASA Administrator) challenge to fly an aircraft on Mars on the $100^{\text {th }}$ anniversary of the Wright brothers historic flight at Kitty Hawk. ${ }^{4}$ With a mandate from the NASA Administrator, a large number of personnel across several NASA research centers were assigned to the task and a significant amount of work was accomplished in a very short period of time. In order to fit the Ariane 5 secondary payload ring, aeroshell diameter was limited to just $0.8 \mathrm{~m}$. The small size made efficient packaging a critical issue, both in terms

2

American Institute of Aeronautics and Astronautics 
of packaging the airplane in the aeroshell and packaging the airplane systems in the airplane. Significant effort was directed at exploring different packaging schemes to fit the small aeroshell diameter. Aerodynamic design of the Micromission airplane (referred to as the Mars Airplane Package or MAP in Mars Micromission nomenclature) was also a challenge due to the extremely low Reynolds number, high subsonic Mach number flight regime. Initial concept exploration was conducted by teams at Ames Research Center, ${ }^{5}$ Dryden Flight Research Center and Langley Research Center. Concepts were also later developed by industry teams. One of the NASA developed MAP airplane concepts is illustrated in Figure 1. This rocketpowered airplane had a design mass of $19 \mathrm{~kg}$ with a payload mass allowance of $2.6 \mathrm{~kg}$. Wing area was 0.67 $\mathrm{m}^{2}$ and wing span was $1.73 \mathrm{~m}$. The nominal cruise Mach number was 0.65 with a wing Reynolds number of around 50,000. The fuel load of $3.2 \mathrm{~kg}$ provided 20 min of powered flight and a powered range of $200 \mathrm{~km}$. Aircraft performance and potential science return was severely limited by low maximum lift and high drag resulting from the low Reynolds number, high Mach number flight condition. However, the goal of the MAP was not to return extensive amounts of science data, but to demonstrate the ability to use a Mars airplane as a science platform. The Mars airplane Micromission project was cancelled in November 1999. Although the ARES airplane is much larger than the MAP airplane, the analysis and testing done during the MAP project provided a strong foundation for the ARES airplane design.

\section{DESIGN REQUIREMENTS AND PHILOSOPHY}

Unlike the MAP project, the focus of the ARES mission is not on the airplane but on Mars science. The regional-scale, high-resolution measurements from ARES will provide fundamental new understanding of the nature and variability of the Mars atmosphere, surface, and interior. ${ }^{6}$ Although flying an airplane on Mars is certainly an exciting aeronautical event, from a mission perspective the airplane is simply a platform with which to accomplish the science objectives. The general design philosophy that was adopted for the ARES airplane was to look for the simplest, most robust means to meet the science requirements. Minimizing the risk, complexity, and cost of the airplane system was a primary driver in design decisions. For example, the risk associated with a complex folding scheme such as used for the DSI Astroplane would not be acceptable for the ARES airplane. Extensive airplane technology development would be counter to the low-risk, science focused ARES philosophy. The fact that the ARES mission was part of a competitive selection process also influenced design decisions. To have a successful proposal the airplane design needed to not only meet the mission requirements but also be robust and practical from the perspective of the proposal evaluators.

Some specific requirements for the ARES airplane design are listed in Table 1. The aeroshell size is much larger than for the 1999 Micromission airplane. This enables a larger airplane and flight in a more predictable and better understood flow regime, although still significantly different from that typical of an Earth aircraft.

Table 1. ARES Airplane Design Requirements

- Fit within a $2.65 \mathrm{~m}$ diameter Viking-derivative aeroshell shape (max. internal diameter of $2.48 \mathrm{~m}$ )

- Survive G, radiation, and thermal environments associated with launch, 12+ month transit to Mars, and atmospheric entry

- Provide a stable observation platform - maintain sub-pixel smear in worse case turbulence

- Autonomously navigate a specified ground track - altitude 1-2 km above ground level (AGL), variation of $<10 \%$ over $10 \mathrm{~km}$ - range $\geq 500 \mathrm{~km}$

- Telemetry science data collected during flight - maneuvering restricted to maintain comm. link - useful endurance limited by comm. window

The return of science data to Earth is an important consideration for the mission. Unlike Earth, Mars does not have a constellation of satellites which can provide a continuous, high data rate communication link. In the DSI mission, global communication coverage was to be provided by inserting the three carrier spacecraft in orbit. ${ }^{3}$ In the ARES mission architecture, the primary communication link is provided by the carrier spacecraft executing a fly-by maneuver. The fly-by trajectory, airplane flight path, and transmitter power establish a limit on the total data volume which can be transmitted from the airplane to the carrier spacecraft, and ultimately to Earth. The limited data volume has an important consequence for the airplane design. Although one is inclined to strive for maximum range and endurance, collecting data which cannot be returned to Earth does not have value. There is a point, therefore, at which additional airplane performance may not yield any increase in the scientific value. This again leads to finding a design that is "good enough" to perform the mission, as opposed to maximizing performance. (Note: The concept of post-flight data transmission was considered for the ARES mission and 
rejected due to the large mass penalty associated with a survivable data package and the increased risk of loss of data.)

\section{ARES AIRPLANE CONCEPT EXPLORATION}

The current ARES airplane design, referred to as ARES-2, is illustrated in Figure 2. This design is the result of a concept exploration and evolution involving a number of trade studies, downselects, and design refinements. The ARES airplane concept development team encompassed a broad range of expertise across NASA (Langley, Ames, and Glenn Research Centers), industry (Aurora Flight Sciences), and academia (Stanford University and Massachusetts Institute of Technology (MIT)). Ideas and concepts were generated and evaluated by team members both individually and collectively. Major areas of consideration during the concept development included: aeroshell packaging approach, propulsion, tail arrangement, and wing geometry.

\section{Methodology for Concept Exploration}

Evaluation of a wide variety of concepts, to varying levels of detail, guided the concept selection process.

Comparative aerodynamic analysis focused on the primary design drivers for the ARES mission: stability and control, maximum lift, and lift-to-drag ratio (L/D). General stability and control characteristics were assessed using an inviscid, vortex lattice analysis code, VORVIEW. VORVIEW was developed at NASA Ames and is an enhancement of the VORLAX code developed by Lockheed in the 1970's. ${ }^{7}$ The VORVIEW graphical user interface allows the user to interactively define control surface locations and the vortex lattice paneling. Stability and control derivatives can be calculated using an automated routine which perturbs flight conditions and control surface deflections. Input geometry for VORVIEW was generated with the Rapid Aircraft Modeler (RAM) aircraft geometry tool also developed at NASA Ames. ${ }^{8}$ While a vortex lattice analysis cannot capture viscous effects on the configuration stability and control, it was an appropriate tool for configuration screening and assessing fundamental stability and control issues.

Maximum lift capability and L/D characteristics directly impact the ability of the design to meet the science mission goals. Prediction of maximum lift coefficient $\left(\mathrm{C}_{\text {Lmax }}\right)$ and drag requires methods which encompass viscous flow effects. Unfortunately, typical "handbook" type estimates for these parameters do not adequately reflect the unusual Mach and Reynolds number flight regime of a Mars airplane. Of particular importance is the potential for unusual boundary layer behavior (such as separation bubbles) which can significantly impact the lift and drag characteristics. Since it was impractical to perform a viscous, 3-D computational fluid dynamics analysis for each configuration considered, a coupled 2-D/3-D analysis approach was employed. Airfoil section characteristics were estimated using the MSES code developed by Mark Drela of MIT. ${ }^{9}$ MSES couples a streamwise Euler discretization of the flow with an integral boundary layer formulation. It has been previously used for both low Reynolds number and transonic applications. Good agreement between MSES and 2-D Navier-Stokes solutions has been demonstrated at ARES airplane flow conditions. ${ }^{10}$ The airfoil characteristics were extended to 3-D aerodynamic predictions using a non-linear Weissinger method developed at UC-Davis. ${ }^{11}$ This method is similar to a non-linear lifting line method, such as presented by Anderson. ${ }^{12}$ The method combines viscous airfoil data (from wind tunnel or computational analysis such as MSES) with inviscid, 3-D lifting surface theory. Viscous drag and pitching moment effects are captured in a stripwise integration using the input viscous airfoil characteristics. When a local $\mathrm{C}_{1}$ reaches $\mathrm{C}_{\mathrm{lmax}}$ at some span location, the solution procedure usually becomes unstable and analysis at higher angles of attack is not possible. The total configuration $\mathrm{C}_{\mathrm{L}}$ at this point was considered the approximate $\mathrm{C}_{\mathrm{Lmax}}$, since local $\mathrm{C}_{\mathrm{l}}=\mathrm{C}_{\mathrm{lmax}}$ is an often-used criterion for estimating $\mathrm{C}_{\mathrm{Lmax}}$ in conceptual design. Since drag results from the nonlinear Weissinger code only include the lifting surfaces, traditional estimation techniques were used to add drag for other components.

Early comparative analysis of the total mass and overall mission performance of various design options was conducted using spreadsheet-based analysis. Airframe and system masses were estimated based on previous studies and simple relationships. Propulsion system characteristics were based on data for existing systems or on expert opinion. Range performance for a specific fuel (or battery) mass was determined through a time step integration.

After the concept was selected, higher fidelity analysis methods were applied, including finite element structural analysis, 3-D computational fluid dynamics analysis, and six degree-of-freedom airplane mission simulations.

\section{Aeroshell Packaging Approach}

The ARES airplane is delivered to Mars in the Viking derivative aeroshell shape shown in Figure 3. This 
shape is not ideal in terms of maximizing airplane size and performance, but was selected because of aeroshell design heritage. Packaging in the aeroshell is complicated by a parachute canister which extends through the middle of the aeroshell interior and six separation fittings around the perimeter, i.e. where the backshell and heat shield of the aeroshell attach.

The lowest risk packaging approach is to simply make the airplane small enough to fit inside the aeroshell in the flight configuration. Unfortunately, the resulting wing area for a $2.65 \mathrm{~m}$ aeroshell limits the maximum airplane mass to values that are too low to meet the ARES science payload and range requirements. In order to get sufficient wing area some type of airplane stowage in the aeroshell is necessary.

Using a non-rigid wing takes most advantage of the available aeroshell volume. One possibility is a Rogallo type parawing. ${ }^{13}$ Another concept, which has been demonstrated on Earth, is an inflatable wing. ${ }^{14}$ Flexible or inflatable structure could also be used to add wing area to a rigid structure. The main issue with nonrigid wing concepts was the additional risk entailed over a conventional structure. Of particular concern was the performance of flexible materials after being exposed to a cold environment for the approximately one year transit to Mars. Although this issue could likely be resolved, the need for qualification and perhaps development of appropriate materials was deemed an unacceptable additional program risk.

A conventional rigid structure can be built with spacequalified materials. Options for stowage of rigid structures include folding or telescoping mechanisms. A number of past space systems have used telescoping mechanisms. There is a history, however, of problems with these mechanisms. Spring-loaded folds were considered the simplest, lowest risk packaging approach. Since there is still risk involved in the aircraft unfolding, minimizing the number of folds was a design objective. The basic wing folding scheme was based on one developed during the MAP project in which the outer wing panels are folded on top of each other as illustrated in Figure 4. This approach allows a large wing area to be obtained with only two wing folds (one on each side).

\section{$\underline{\text { Propulsion }}$}

Low atmospheric density and the lack of appreciable amounts of atmospheric $\mathrm{O}_{2}$ complicate propulsion for a Mars airplane and lead to consideration of unconventional (from an Earth airplane perspective) propulsion options. There are several approaches for dealing with a lack of atmospheric $\mathrm{O}_{2}$. Use of a monopropellant fuel or carrying both fuel and oxidizer on-board enables combustion without atmospheric $\mathrm{O}_{2}$. (Note that since one of the ARES science objectives is measurement of trace atmospheric gases, the mission must be planned such that combustion exhaust products do not contaminate these measurements.) Another approach is to use energy from some type of on-board battery or nuclear device. Energy can also be obtained from an off-board source such as solar energy or a directed energy system. Solar powered airplanes have to be quite large to collect sufficient solar power and typically have small payload mass fractions. Power density (watts per collector area) can be made higher with a directed, or "beamed," energy system, but total system and mission complexity is greatly increased. The thrust problems associated with low atmospheric density can be dealt with either by designing a suitable propulsor (e.g., a large propeller) or by using a method of propulsion which does not depend on the presence of an atmosphere (e.g., a rocket).

Propulsion options considered for the ARES airplane included: no propulsion (glider), rocket (liquid or solid), and propeller (driven by various power sources).

A glider is attractive because of the mass, cost, and risk reduction associated with eliminating the propulsion system. The obvious downside to a glider is that the range is limited, being determined by the airplane glide slope and the starting altitude. Meeting the ARES $500 \mathrm{~km}$ range requirement with a glider would require an unrealistically high L/D or deployment altitude. The high altitude portion of the resulting flight would not be compatible with the 1-2 km AGL altitude requirement. There is also a science driven requirement to hold altitude to within $10 \%$. With a glider, altitude can only be held for a short time before velocity drops to the stall velocity. The performance requirements dictated by the ARES science objectives cannot be met with a glider.

Being the preferred propulsion approach for the MAP airplane, rocket propulsion was considered for the ARES airplane as well. Rocket propulsion was deemed the lowest risk option (excluding the glider option) because of its space heritage and robust thrust generation. Solid rocket motors are inherently simple and their use was briefly considered. However, the need for controlled thrust over a long duration greatly increases the complexity of a solid rocket system. This led to exploring liquid rocket systems and investigation revealed that liquid rocket thrusters in the right thrust class for the ARES airplane had already been designed and tested. Using one of these systems would greatly 
reduce the propulsion system development cost and risk. The rocket propulsion system does present some challenges. The relative inefficiency of a rocket system negatively impacts the airplane range and endurance, although the mission requirements can still be met. Also, the rocket exhaust plume must be considered in determining the airplane layout.

A number of propeller based propulsion systems were considered for the ARES airplane. A propeller can be a more efficient means of generating thrust than a rocket and has been the propulsion choice for most past Mars airplane concepts and low-speed, high-altitude Earth aircraft. Options considered for driving the propeller included an electric motor powered by batteries, an electric motor powered by a fuel cell, and the Akkerman type hydrazine engine. The thin Martian atmosphere makes heat rejection a significant issue for all three of these systems. None of these propeller based propulsion systems are "off-the-shelf" and would require design and development before they could be implemented on the ARES airplane. Selection of a propeller based system was therefore considered to have significant cost and risk implications.

A liquid rocket propulsion system was ultimately selected for the ARES airplane design, not because it offered the highest potential airplane performance, but because it was the lowest risk, lowest cost system which enabled the science objectives to be met. If the primary design focus had been to maximize aircraft performance, and funding was allocated accordingly for propulsion system development, the rocket system would likely not have been the preferred concept. Even so, the performance penalty of a rocket system is not as large as it might initially appear. The fuel mass benefit of a propeller based system compared to a rocket is much less on Mars than on Earth, because of the nonair-breathing power system required to drive the propeller. Furthermore, for the mission duration necessary to meet the ARES science objectives, the reduction in fuel mass is largely offset by a higher system mass. Following additional trades on the liquid rocket propulsion system, a regulated, bi-propellant system providing nominally $60 \mathrm{~N}$ of thrust was chosen. It was determined that the airplane control system could be configured to maintain the required altitude and speed tolerances with pulsed (on/off) operation of the rocket. This allowed the additional complexity of a throttleable rocket system to be avoided.

\section{Tail Arrangement}

Having established that the ARES airplane would be rocket-powered and have a rigid, folding structure, various aircraft layouts and packaging schemes were investigated. Of particular importance was the tail arrangement. Without telescoping structure the aeroshell packaging constraints lead to short control moment arms. Maximizing this moment arm and the stabilizer surface area is therefore important for achieving acceptable airplane stability and control.

Early in the concept exploration phase some consideration was given to a canard-wing arrangement. This type of layout had clear propulsion integration advantages over a tailed configuration, and may have been a viable candidate if not for aeroshell packaging constraints. Achieving the canard control power necessary for adequate closed-loop stability performance tends to require an aft wing placement. This need for an aft wing placement had to be balanced against the need for wing area, which is best obtained with the wing positioned near the aeroshell center. Achieving adequate stability was also made difficult by aeroshell center-of-gravity (c.g.) constraints. For spin stability the c.g. of the aeroshell with the airplane inside needs to be on the aeroshell centerline. Although it is possible to use ballast to adjust the entry system c.g., large deviations of the airplane folded c.g. from the aeroshell centerline cannot be accommodated. For the canard configuration the desired airplane c.g. from an airplane stability point of view was significantly offset from the aeroshell centerline. The mismatch between the required airplane and aeroshell c.g. locations coupled with the wing area penalties associated with an aft wing led the design team away from a canard configuration.

Considerable attention and analysis was applied to four other possible arrangements before arriving at the final "inverted V-tail" configuration. Ideas investigated included: tailless (flying wing), conventional tail, wingtip tails, and split tails. Versions of these concepts are shown in Figure 5. An example of the type of comparative quantitative analysis performed is contained in Table 2. Ultimately, predicted aerodynamic performance and stability and control were not the primary discriminators among the concepts. Many other factors, which were considered through qualitative evaluation, influenced the concept selection. 
Table 2. Example Concept Comparison

\begin{tabular}{|l|c|c|c|}
\hline Tail Arrangement & Tip & Split & Center \\
\hline HT Area, cm2 & 9780 & 9780 & 12,280 \\
\hline Aerodynamic Center, cm & 141 & 130 & 132 \\
\hline Analyzed CG, cm & 136 & 125 & 126 \\
\hline Static Margin & $5.0 \%$ & $5.2 \%$ & $5.2 \%$ \\
\hline HT Volume Coefficient & 0.24 & 0.37 & 0.37 \\
\hline \multicolumn{4}{|c|}{ Trim @ $\mathrm{C}_{\mathrm{L}}=0.7$} \\
\hline Delta flap, deg & -17.5 & -11.1 & -7.0 \\
\hline Wing max section $\mathrm{C}_{\mid}$ & 0.84 & 0.87 & 0.87 \\
\hline Tail max negative $\mathrm{C}_{\mid}$ & -0.33 & -0.51 & -0.43 \\
\hline Total induced $\mathrm{C}_{\mathrm{D}}$ & 0.0412 & 0.0354 & 0.0346 \\
\hline
\end{tabular}

The flying wing configuration was appealing for its propulsion integration and folding simplicity, having just two folds (one for each side of the wing). While not a common layout, there have been a number of successful flying wing airplane designs over the years. The lack of a separate trimming surface does limit the amount of pitching moment that can be trimmed, however. Since high airfoil $\mathrm{C}_{\mathrm{Imax}}$ is usually accompanied by large nose-down pitching moment, the flying wing configuration was expected to have lower maximum lift capability than the tailed configurations. The lack of a tail simplified the airplane unfolding, but also introduced the potential for a higher risk of entering a spin or tumble during deployment. Spin and tumble susceptibility can be addressed through proper design. Nevertheless, the susceptibility of tailless designs to adverse flight motions initiated from unusual attitudes (as would be encountered at the onset of the ARES airplane deployment sequence) was the basis for eliminating the flying wing design from further consideration.

A conventional tail configuration was developed based on design work done during the MAP project. The primary consideration in this arrangement was positioning of the tail away from the rocket exhaust plume. The horizontal tail was positioned below the rocket plume and the twin vertical surfaces were positioned to the either side of the plume. This arrangement allowed a large tail area and the configuration was found to have acceptable aerodynamic performance. There were a couple of risk related disadvantages. First, this concept had the highest number of folds (5). Since unfolding events were deemed risk items and the objective was to minimize the number of folds, this fact weighed heavily against the concept. Second, it was felt that there would be a potential risk associated with the proximity of the tail to the rocket exhaust. Of particular concern were the effects of the rocket plume on the tail thermal environment and the non-linear control behavior which might result from changes in tail flow conditions caused by the plume.

The wingtip tail arrangement was also based on previous design work for the MAP mission. Positioning of the tail surfaces at the wingtips placed them far from the rocket exhaust plume. The primary aerodynamic advantage of this concept was a reduction in the amount of tail download necessary to trim the aircraft, leading to higher configuration trimmed $\mathrm{C}_{\mathrm{Lmax}}$ capability. However, the wingtip booms generated some concern from a structural standpoint. Additionally, this arrangement offered the least flexibility in exploring different wing planforms and folding schemes, due to the direct coupling between the tail and wing folding. (For all configurations the wing and tail folding are somewhat dependent on each other.)

In the twin, "split tail" concept the rocket plume issue was addressed by basically splitting the tail into two separate halves placed to either side of the rocket plume. Aerodynamic performance was found to be similar to the conventional tail arrangement. Although there are two tails, the number of events in the unfolding sequence (4) was one less than the conventional configuration, implying lower deployment risk. As with the wingtip tail concept, the tail booms were a cause of some concern from a structural standpoint. Having the booms connected near the wing root was felt to be less of a problem than at the wing tips, however. Out of the four concepts shown in Figure 5, this was selected as the preferred concept.

While the split tail configuration was being further developed and refined, it was observed that there was no real reason for the two tails to be completely independent. This observation led to consideration of an inverted V-tail arrangement. With a single tail there are just three unfolding events and the single tail also gives a higher effective tail aspect ratio than the split tail. Another advantage is that only four control surfaces are needed. The rocket exhaust issue was addressed with a high tail placement and a negative dihedral angle that maintained a sufficient distance from the plume for the entire span. Initially, the problem with the inverted V-tail concept was the small chord available in the center of the tail due to packaging constraints. This problem worsened as the height of the tail was increased for better lateral/directional stability. The key to packaging a larger tail was found to be deflecting the full span control surfaces downward such that they lie along the slope of the backshell. Since the surfaces overlap at large deflections, one surface is deflected more than the other. This deflection is 
effectively a folding of the tail chord and greatly increases the tail area that can be packaged into the aeroshell. Since this "folding" is simply extra travel on the control surface servos, it incurs no reliability penalty. As shown in Figure 6, the V-tail shape with deflected control surfaces fits nicely in the conical backshell of the aeroshell. Two booms, positioned to avoid interference with the parachute canister, are used to connect the tail to the fuselage. These tail booms are not subjected to the type of torsional loads present for the split tail or wingtip tail arrangements.

The reduction in boom structural issues, improved aerodynamics, and fewer unfolding events made the inverted V-tail concept preferred over the previously selected split tail arrangement.

\section{Wing Geometry}

During the MAP project a number of wing planform trade studies were conducted which served as a starting point for the ARES design. One of the studies was a parametric variation in wing sweep and wing position (relative to the aeroshell) to examine the resulting trends in wing area and static pitch stability. The results of that study indicated that with the desire for the aircraft c.g. to be near the aeroshell center, the optimum wing sweep was around $10^{\circ}$. This was the basis for the simple planform shown on the conventional and split tail configurations in Figure 5. One of the assumptions made for this initial planform was that the wing hinge lines would be perpendicular to the wing leading edge. However, with this approach the folded wing "stack" requires the hinges on one side to have a lot of offset to clear the other wing. The use of canted hinge lines reduces the thickness of the stack and eliminates the need for offset. The wing hinges can therefore be simpler and lighter. A canted hinge line also allows the folded outboard wing trailing edge to be placed close to a diameter line of the aeroshell, resulting in maximum span at the trailing edge. In addition, hinge line sweep increases the aiding aerodynamic forces during deployment. Making the hinge line sweep angle independent from the wing leading-edge sweep introduced an additional degree of freedom in the folding and expanded the planform shape options. Another change from the initial, simple planform shape was the addition of a sweep break at the fold location. Planform shape inboard of the hinge has relatively little impact on the folding. By increasing the inboard leading-edge sweep to $30^{\circ}$, it was possible to increase total planform area without changing the geometry of the folded wing panels.
The folding of a rigid wing structure into the entry aeroshell presents a number of unique considerations in selection of a wing planform shape. There is a trade-off between wing area and aspect ratio that must be considered. For most airplanes wing area and aspect ratio can be selected somewhat independently, with aspect ratio usually a trade-off between aerodynamic performance and structural weight and wing area often dictated by takeoff or maneuver requirements. For the ARES airplane, fitting the wing into the circular aeroshell restricts the possible wing area-aspect ratio combinations.

Possible planform shapes were explored extensively, and a spreadsheet-based geometry analysis routine was developed which permitted some geometry/folding optimization to be performed. Using this spreadsheet an investigation of the trade-off between wing area and aspect ratio was performed. The results of this investigation are shown in Figure 7. Figure 7 clearly shows the drop off in the maximum wing area that can be achieved as aspect ratio is increased. Note that for this investigation the theoretical location of the wing aerodynamic center was also constrained to avoid large deviations of the required aircraft c.g. from the aeroshell center. Although important to establish the limits and trade-offs between wing area and aspect ratio, the results by themselves do not point to an obvious planform choice. Selecting a large wing area, at the expense of aspect ratio, might permit a larger airplane mass capability. With the larger mass capability, the additional fuel carried could possibly offset the decrease in aerodynamic performance (L/D) resulting from the lower aspect ratio. On the other hand, increasing aspect ratio would tend to decrease the amount of fuel, and therefore airplane mass, necessary to achieve a given range. Another consideration is the increase in wing downwash associated with a low aspect ratio wing. Coupled with a limited tail size and moment arm, the negative effect of higher wing downwash on tail effectiveness could cause stability and control issues. Based on the experience of team members, results from the MAP project, and preliminary pullout analysis, a baseline planform with an aspect ratio of 6 , and wing area of $7.0 \mathrm{~m}^{2}$ was selected.

For simplicity, most of the initial planform trade studies were conducted assuming the wing was folded in a cylinder, i.e. the decrease in aeroshell diameter with height was not included. Once a baseline planform was selected, more rigorous 3-D packaging into the aeroshell was conducted. In addition to the aeroshell taper, another complication was the separation fittings.

8

American Institute of Aeronautics and Astronautics 
These fittings protrude into the envelope available for the airplane and clearing them required adjustment in the planform shape and folded geometry. Accommodating the real 3-D packaging constraints involved a number of refinements to the planform shape, leading the final ARES airplane planform shape.

Once a planform shape was established, a study of the wing twist and airfoil distribution was initiated. The wing twist and airfoil distribution were not formally optimized, but determined through parametric analysis. For simplicity, only linear wing twist was considered. A washout of $3^{\circ}$ on the outboard panel was found to provide a nearly elliptical lift distribution, based on a vortex lattice analysis of the wing. Several airfoil shapes were designed for the ARES airplane with varying pitching moment and maximum lift capability $\left(\mathrm{C}_{\text {lmax }}\right){ }^{8} \quad$ Two airfoils were considered for the ARES-1 wing, ssle and ss1f. In choosing an airfoil distribution for the wing, the general philosophy was to only use the higher lift capability ss $1 \mathrm{f}$ airfoil where necessary, since this airfoil entailed a nose-down pitching moment penalty. A vortex lattice analysis of the planform shape was conducted to determine the section $\mathrm{C}_{1}$ distribution and the critical region for high lift capability. The highest local section $\mathrm{C}_{1}$ is at and around the leading edge "kink." As shown in Figure 8, the ss1f airfoil was applied in this area, extending inboard and outboard of the kink until the drop in section $C_{1}$ from the value at the kink was slightly greater than the difference in $\mathrm{C}_{\text {lmax }}$ between the ssif and ssle airfoils. This was done to avoid wing stall beginning in an ssle region of the wing, which would have not allowed the full lift potential of the ss 1f airfoil to be exploited.

The concept downselect and design evolution discussed above led to the ARES-1 airplane concept shown in Figure 9, which was detailed in the Step 1 Mars Scout proposal for the ARES mission. This configuration reflects the extensive airplane design experience of the team members and knowledge acquired in the area of Mars airplane design during both the MAP project and ARES proposal effort. Table 3 contains a summary of key parameters for this configuration.
Table 3. ARES-1 Geometric Parameters

\begin{tabular}{|l|c|}
\hline Wing Span & $6.33 \mathrm{~m}$ \\
\hline Overall Length & $4.3 \mathrm{~m}$ \\
\hline Overall Height & $0.7 \mathrm{~m}$ \\
\hline Reference Area & $7.11 \mathrm{~m}^{2}$ \\
\hline Reference Chord & $1.20 \mathrm{~m}$ \\
\hline Wing Aspect Ratio & 5.64 \\
\hline Wing Sweep (LE) & $30^{\circ} / 13^{\circ}$ \\
\hline Tail Anhedral & $34^{\circ}$ \\
\hline Projected Horizontal tail Area & $0.88 \mathrm{~m}^{2}$ \\
\hline HT Volume Coefficient & 0.28 \\
\hline Projected Vertical Tail Area & $0.3 \mathrm{~m}^{2}($ each) \\
\hline VT Volume Coefficient & 0.035 (total) \\
\hline
\end{tabular}

\section{DESIGN REFINEMENT}

The ARES-1 configuration was developed in a relatively short amount of time following the concept exploration phase. The geometry for this design was frozen for the Mars Scout Step 1 proposal only a few months after the initial downselect to the basic concept of a rigid airframe with rocket propulsion. Further development continued throughout and following submittal of the Step 1 proposal and incorporated results from a successful high-altitude drop test of the design (slightly altered for rapid prototype flight testing). ${ }^{15}$ Attention was given to maturing and refining the ARES-1 configuration with a particular interest in improving control margins and L/D. The three primary areas of focus during the design refinement were the wing airfoil distribution, the fuselage shape, and the tail geometry.

\section{Wing airfoil distribution}

In order to increase pitch control margins and reduce trim drag, additional effort was applied to reducing the wing zero lift pitching moment $\left(\mathrm{C}_{\mathrm{mo}}\right)$ while not adversely impacting the maximum lift capability. For the ARES-1 airfoil and $\mathrm{C}_{1}$ distribution shown in Figure 8 , when the "kink" section reaches $\mathrm{C}_{\text {lmax }}$, the inboard sections are well below their maximum lift capability. This indicates that a lower camber, lower pitching moment airfoil could be used in this region of the wing, without impacting the maximum lift capability of the wing. Recognizing this potential, an additional wing airfoil with less camber than ssle was designed for the inboard region of the wing (referred to as sslb). ${ }^{8}$ Another change made in the airfoil distribution was to define the airfoils at three span locations and use a simple linear lofting between these stations, rather than having areas of constant airfoil shape as in ARES-1. The highest $\mathrm{C}_{\operatorname{lmax}}$, highest pitching moment airfoil section (ss1f) was only used at the most critical "kink" location. In order to maintain the nearly elliptical

9

American Institute of Aeronautics and Astronautics 
spanloading of ARES-1 with this new airfoil distribution, a new wing twist distribution was also necessary. In particular it was necessary to add positive incidence to the inboard portion of the wing, which has less camber than in ARES-1. A linear twist was used between the three airfoil defining stations. The old and new twist distributions are compared in Figure 10.

The lift coefficient distribution for the new airfoil and twist distribution is shown in Figure 11. (Note: Inboard wing sections and twist were slightly modified during later wing/fuselage blending.) The new airfoil and twist distribution resulted in a $22 \%$ decrease in wing $\mathrm{C}_{\text {mo }}$ (i.e., less nosedown), with no impact on the predicted wing $\mathrm{C}_{\text {Lmax }}$. This reduction in wing $\mathrm{C}_{\mathrm{mo}}$ decreased the amount of tail download necessary to trim the configuration, which had a number of benefits. With the same wing $\mathrm{C}_{\mathrm{Lmax}}$ and a lower download on the tail, the overall configuration trimmed $\mathrm{C}_{\mathrm{Lmax}}$ was slightly higher. Secondly, there was a reduction in trim drag, improving L/D. Finally, with less tail load needed to trim there was an increase in the pitch control margin.

\section{Fuselage shape}

In the ARES-1 concept exploration a lot of attention was given to the propulsion system, wing design, and tail design with less emphasis given to the fuselage design.

The ARES-1 fuselage shape was primarily driven by three considerations. First was airplane packaging in the aeroshell. To get the most wing area, the wing needs to fold at or near the maximum aeroshell diameter and into the backshell where the diameter remains relatively high. This results in the fuselage being in the heat shield portion of the aeroshell (see Figure 9a). This location for the fuselage also helps to keep the c.g. of the aeroshell+airplane close to the heat shield for good stability during atmospheric entry. The second influence on fuselage shape was the fuel and oxidizer tanks, which are the largest items that must fit in the fuselage. Due to space heritage and certification issues only spherical or cylindrical tank shapes were considered. The fuselage shape was wrapped around two cylindrical tanks, which need to be placed near the airplane c.g. to avoid large c.g. movement as the fuel is used. The final fuselage shape consideration was the carry-through structure of the wing. The structural concept for ARES-1 was to have the complete wing structure, including the skins, carry through the fuselage, i.e. to have the fuselage basically sit on top of the wing structure. Adding the tank height (diameter) to the wing root thickness led to a large fuselage depth and camber as sketched in Figure 12a.

While the ARES-1 fuselage permitted a simple wing carry-through structure and had sufficient volume for the airplane fuel tanks, systems, and payload, there were some aerodynamic concerns. One major concern was the expected flow separation on the aft fuselage and the resulting base drag. The possible affect of this fuselage flow separation on the tail flowfield and tail effectiveness was also considered an issue. A second concern was the additional nosedown pitching moment associated with the fuselage camber.

Following the Step 1 proposal submittal, an effort was undertaken to explore new fuselage shapes that would address the aerodynamic concerns with the ARES-1 shape. Improving the fuselage shape by changing to a tapered fuel tank shape was explored, but rejected due to a lack of extensive design heritage. Although the ARES-1 approach allowed for a simple structural integration of the wing and fuselage, the fuselage volume encapsulated by the wing could not be used. Dropping the tanks into this wing volume would reduce fuselage height by $\sim 17 \%$, and camber as well, leading to less fuselage flow separation and less nosedown moment. Due to c.g. considerations, the fuel tanks needed to be placed in the same area as the wing carrythrough structure, which presented a structural arrangement challenge. A significant "breakthrough" was made when it was realized that the width of the two tanks together was not significantly less than the individual tank lengths and therefore the tanks could be placed transverse in the fuselage without significantly increasing the fuselage width. With a transverse tank arrangement it was possible to lower the tanks and have a traditional wing carry-through structure with a main spar between the two tanks. The maximum potential lateral c.g. shift from fuel slosh in this arrangement is readily offset with less than $10 \%$ of the available lateral control. Moving away from the low-wing arrangement of ARES-1 to a mid-wing arrangement allowed a further reduction in fuselage camber. The ARES-2 fuselage-wing arrangement is sketched in Figure 12b. The new fuselage cross-section is basically a derivative of the sslb wing airfoil shape and is much less susceptible to flow separation. Efficient packaging of the mid-wing arrangement in the aeroshell required a negative dihedral angle on the inboard portion of the wing so that the lower surface of the fuselage did not interfere with the wing folding. 
Tail Geometry

Modifications to the tail geometry were made with the desire to increase the airplane control margins. As mentioned previously, to increase the amount of tail area that can be packaged in the aeroshell, the tail control surfaces are deflected when the aircraft is stowed in the aeroshell. To avoid interfering with each other when deflected during flight, these control surfaces cannot extend all the way to the tail centerline. Without this effective chordwise fold at the centerline there is a significant cutout in the tail trailing edge, which reduces the tail effectiveness. Analysis indicated approximately a $20 \%$ reduction in tail effectiveness compared to a tail without this trailing-edge cutout. To facilitate filling this gap, the ARES-2 tail has a horizontal center portion. The current tail geometry has a fixed, partial gap filler, but there is the potential for using a deployable full chord gap filler if additional analysis and testing indicates it is needed. Changes in aeroshell packaging also allowed an increase in the tail area. This improvement was partially the result of drooping the wing tips, which increased the room available for the tail.

General characteristics of ARES-2, shown in Figure 2, are summarized in Table 4 . The ARES- 2 configuration is a more robust design than ARES- 1 . The increase in tail control authority provided by changes in tail design and a reduction in $\mathrm{C}_{\mathrm{mo}}$ give the design excellent control margins for trim over a wide range of angles of attack. The near elimination of fuselage flow separation also alleviates concerns that the tail might be blanketed by the fuselage wake. Analysis indicates more than a 15\% increase in L/D compared to ARES-1 through a reduction in trim drag (lower $\mathrm{C}_{\mathrm{mo}}$ ) and fuselage base drag (less separation). Further refinements to the ARES-2 design are possible as additional analysis and test results become available during the remainder of the design and development period.

Table 4. ARES-2 Geometric Parameters

\begin{tabular}{|l|c|}
\hline Wing Span & $6.25 \mathrm{~m}$ \\
\hline Overall Length & $4.4 \mathrm{~m}$ \\
\hline Overall Height & $0.7 \mathrm{~m}$ \\
\hline Reference Area & $7.0 \mathrm{~m}^{2}$ \\
\hline Reference Chord & $1.25 \mathrm{~m}$ \\
\hline Wing Aspect Ratio & 5.58 \\
\hline Wing Sweep (LE) & $30^{\circ} / 13^{\circ}$ \\
\hline Tail Anhedral & $37^{\circ}$ \\
\hline Projected Horizontal Tail Area & $1.1 \mathrm{~m}^{2}$ \\
\hline HT Volume Coefficient & 0.37 \\
\hline Projected Vertical Tail Area & $0.4 \mathrm{~m}^{2}$ (each) \\
\hline VT Volume Coefficient & 0.053 (total) \\
\hline
\end{tabular}

\section{SUMMARY OF PREDICTED CAPABILITIES}

Aerodynamic estimates for the ARES-2 configuration have been made over a range of Mach and Reynolds number conditions using the aerodynamic analysis technique described previously. These aerodynamic predictions will be verified in the future with wind tunnel and flight testing of the ARES-2 configuration in the relevant low Reynolds number, high subsonic Mach number flow conditions.

Nominal values for key stability and control derivatives for ARES-2 at cruise are shown in Table 5. The aircraft is statically stable and is damped in all axes. The negative dihedral present in the configuration geometry results in weak $C_{1 \beta}$ stability, which is actually desirable to minimize sideslip-to-roll coupling, allowing a more stable pointing platform. Airplane control is provided by flaperons on the wing and ruddervators on the tail. Symmetric flaperon deflection is used for lift augmentation during the pullout maneuver. Sufficient roll control is provided by aileron (asymmetric flaperon) deflection to perform the maneuvers necessary to execute the mission. Aileron deflection causes a small, but manageable adverse yawing moment. Elevator (symmetric ruddervator) control power is sufficient to trim over a large angle-of-attack range throughout the flight envelope. Yaw control is provided by rudder (asymmetric ruddervator) deflection. With the V-tail arrangement, rudder deflection does cause a small nose-down pitching moment. This change in pitching moment is only a fraction of the pitch control provided by symmetric deflection, however.

Table 5. Key Stability and Control Derivatives (cruise)

\begin{tabular}{|c|c|c|}
\hline$\partial \mathrm{C}_{\mathrm{m}} / \partial \mathrm{C}_{\mathrm{L}}:-0.07$ & & \\
\hline \multicolumn{3}{|c|}{ Sideslip Derivatives (per degree): } \\
\hline & $C_{n \beta}: 0.0011$ & $C_{1 \beta}:-0.0005$ \\
\hline \multicolumn{3}{|c|}{ Damping Derivatives (per radian): } \\
\hline $\mathrm{C}_{\mathrm{mq}}:-6.8$ & $C_{n r}:-0.07$ & $\mathrm{C}_{\mathrm{lp}}:-0.42$ \\
\hline \multicolumn{3}{|c|}{ Control Derivatives (per degree): } \\
\hline$C_{m \delta r}:-0.0031$ & $C_{n \delta r}:-0.0014$ & $C_{18 r}:-0.0003$ \\
\hline$C_{m \delta e}:-0.0140$ & $C_{n \delta a}: 0.0002$ & $C_{l \delta a}:-0.0026$ \\
\hline
\end{tabular}

Predicted lift and moment characteristics (without flaperon deflection) for near cruise conditions of $\mathrm{M}=0.65$ and $\mathrm{Re}=200,000$ per meter $\left(\mathrm{Re}_{\mathrm{c}}=250,000\right)$ are shown in Figure 13. As indicated in the pitching moment results, the ARES- 2 configuration is able to

American Institute of Aeronautics and Astronautics 
trim over the complete angle-of-attack range analyzed with less than $10^{\circ}$ of elevator deflection. The tail incidence has been set such that very little elevator deflection is required to trim in the cruise $\mathrm{C}_{\mathrm{L}}$ range. The trimmed $C_{L}$ vs. $\alpha$ curve in Figure 13 ends at the predicted onset of wing stall. With no flaperon deflection, the "stall onset" $\mathrm{C}_{\mathrm{L}}$ is around 1.05 for this Mach and Reynolds number condition. Trimmed L/D characteristics for the same Mach and Reynolds number condition are presented in Figure 14. The predicted maximum $\mathrm{L} / \mathrm{D}$ for these conditions is 14.7 , with $\mathrm{L} / \mathrm{D} \geq$ 14 for the $C_{L}$ range of roughly 0.45 to 0.78 .

Mach and Reynolds number effects on maximum trimmed lift are summarized in Figure 15. The sensitivity of maximum trimmed $\mathrm{C}_{\mathrm{L}}$ to Reynolds number is relatively small. Mach effects are more significant. Predicted maximum lift capability begins to degrade as Mach number exceeds 0.65. A drogue chute is used during the pullout maneuver to prevent the airplane from accelerating too far into this unfavorable high Mach regime, as well as to provide an initial orientation force during deployment. Figure 16 shows nominal pullout performance at the maximum airplane mass of $175 \mathrm{~kg}$. The peak Mach number encountered during this pullout is less than 0.7. As evident in Figure 16, there is a second, lower peak in Mach number after the drogue chute is released. Selecting an appropriate drogue chute size and release criterion is important for limiting Mach number to acceptable values and maximizing pullout performance.

The variation of $\mathrm{L} / \mathrm{D}_{\max }$ with Mach and Reynolds number is shown in Figure 17. Mach and Reynolds number both significantly impact $L / D_{\max }$. Higher Reynolds numbers lead to higher L/D's as would be expected. L/D is also very sensitive to Mach number. $\mathrm{L} / \mathrm{D}_{\max }$ is high at the cruise Mach number, but decreases rapidly for higher Mach numbers, as transonic effects and wave drag begin to add significantly to the total airplane drag.

Predicted cruise performance for ARES-2 is summarized in Table 6. Maximum airplane mass is limited to $175 \mathrm{~kg}$ by pullout performance. The predicted fuel mass necessary to meet the science mission requirement of $500 \mathrm{~km}$ with this pullout mass is $48 \mathrm{~kg}$, implying a maximum dry mass of $127 \mathrm{~kg}$. The current best estimate (CBE) for airplane dry mass is 82 kg. Therefore, dry mass can grow by $55 \%$ before the wet mass necessary to fully achieve the science mission requirements exceeds the maximum pullout mass. The maximum expected dry mass (obtained by applying mass growth factors based on the level of maturity for the various components) is $101 \mathrm{~kg}$. With a fuel load of $48 \mathrm{~kg}$ and this dry mass, the predicted airplane range is $600 \mathrm{~km}$. Maximum cruise $\mathrm{C}_{\mathrm{L}}$ (maximum mass, start of cruise) is $0.71, \sim 30 \%$ below the estimated stall $\mathrm{C}_{\mathrm{L}}$ at cruise conditions. The $60 \mathrm{~N}$ rocket thruster provides sufficient excess thrust for an instantaneous climb rate of $180 \mathrm{~m} / \mathrm{min}(592 \mathrm{ft} / \mathrm{min})$ at the maximum mass condition.

Table 6. Predicted Cruise Performance for ARES-2*

\begin{tabular}{|l|c|c|}
\hline & $\begin{array}{c}\text { Maximum } \\
\text { Pullout Mass }\end{array}$ & $\begin{array}{c}\text { Maximum } \\
\text { Expected Mass }\end{array}$ \\
\hline Mass, full fuel & $175 \mathrm{~kg}$ & $149 \mathrm{~kg}$ \\
\hline Mass, zero fuel & $127 \mathrm{~kg}$ & $101 \mathrm{~kg}$ \\
\hline Vstall (full) & $116 \mathrm{~m} / \mathrm{s}$ & $107 \mathrm{~m} / \mathrm{s}$ \\
\hline $\mathrm{C}_{\mathrm{L}}$ & 0.52 to 0.71 & 0.41 to 0.61 \\
\hline $\mathrm{L} / \mathrm{D}$ & 14.0 to 14.4 & 13.3 to 14.4 \\
\hline T/W (full) & 0.093 & 0.109 \\
\hline Ps (full) & $180 \mathrm{~m} / \mathrm{min}$ & $329 \mathrm{~m} / \mathrm{min}$ \\
\hline Range & $500 \mathrm{~km}$ & $600 \mathrm{~km}$ \\
\hline Endurance & $60 \mathrm{~min}$ & $71 \mathrm{~min}$ \\
\hline
\end{tabular}

*nominal conditions: $\rho=0.0132 \mathrm{~kg} / \mathrm{m}^{3}, \mathrm{~V}=140 \mathrm{~m} / \mathrm{s}$,

$$
\mathrm{M}=0.65, \mathrm{Re}=180 \mathrm{k} \text { per } \mathrm{m}
$$

\section{CONCLUDING REMARKS}

There are a number of challenges associated with getting an airplane to Mars and flying through the Martian atmosphere. A Mars airplane is feasible, however, and the recognized advantages of performing science observations from an aerial platform has led to numerous Mars airplane studies and concept development efforts over the past quarter-century. This breadth of Mars airplane design knowledge has both directly and indirectly influenced the ARES airplane design. Although airplane technology development has been a significant component of some previous Mars airplane projects, the focus for a Mars Scout mission has to be Mars science. To make the ARES proposal as strong as possible, minimizing airplane related cost and risk was an important design objective. This focus on cost and risk led to some design features which deviate from previous Mars airplane designs. Despite cost, complexity, and size constraints, through concept evolution and refinement a design resulted which enables the high-value science objectives of the ARES mission to be accomplished while also fulfilling the desire for a relatively simple, low-risk science platform. 


\section{REFERENCES}

1. von Braun, W.: The Mars Project. University of Illinois Press, 1953.

2. Wright, H. S.; Croom, M. A.; Braun, R. D.; Qualls, G. D; and Levine, J. S.: ARES Mission Overview Capabilities and Requirements of the Robotic Aerial Platform. AIAA 2003-6577, 2003.

3. A Concept Study of a Remotely Piloted Vehicle for Mars Exploration. NASA CR-157942, 1978.

4. Berger, B.: NASA Proposes Low-Cost Mars Micromissions. Robotic Airplane Would Follow Up Surveyor Findings. Space News, Feb. 22, 1999, p. 6.

5. Smith, S. C.; Hahn, A. S.; Johnson, W. R.; Kinney, D. J.; Pollitt, J. A.; and Reuther, J. J.: The Design of the Canyon Flyer, an Airplane for Mars Exploration. AIAA 2000-0514, 2000.

6. Levine, J. S.; et. al.: Science from a Mars Airplane: The Aerial Regional-scale Environmental Survey (ARES) of Mars. AIAA 2003-6576, 2003.

7. Miranda, L. R.; Elliot, R. D.; and Baker, W. M.: $A$ Generalized Vortex Lattice Method for Subsonic and Supersonic Flow Applications. NASA CR 2865, 1977.

8. Gloudemans, J.R.; Davis, P. C.; and Gelhausen, P. A.: A Rapid Geometry Modeler for Conceptual Aircraft. AIAA 96-0052, 1996.

9. Drela, M.; and Giles, M.: Viscous-Inviscid Analysis of Transonic and Low Reynolds Number Airfoils. AIAA Journal, vol. 25, no. 10, 1987, pp. 1347-1355.

10. Smith, S. C.; Guynn, M. D.; Streett, C. L.; and Beeler, G. B.: Mars Airplane Airfoil Design with Application to ARES. AIAA 2003-6607, 2003.

11. Vander Kam, J.C.: Reduced-Order High-Fidelity Methodologies for the Design of Civil Transport High-Lift Systems. M.S. Thesis, University of California at Davis, 2000.

12. Anderson, J.D., Jr.: Fundamentals of Aerodynamics. Second ed., McGraw-Hill, Inc.,1991.
13. Rogallo, F. M.; Croom, D. R.; Sleeman, W. C., Jr.: Flexible Wings for Transportation. Proceedings of the Intersociety Conference on Transportation, Washington, D.C., May 31-June 2, 1972, Society of Automotive Engineers, 1972, pp. 237-247.

14. Murray, J. E.; Pahle, J. W.; Thornton, S. V.; Vogus, S.; Frackowiak, T.; Mello, J. D.; and Norton, B.: Ground and Flight Evaluation of a Small-Scale Inflatable-Winged Aircraft. AIAA 2002-0820, 2002.

15. Ledé, J-C. M.; Croom, M. A.; and Parks, R. W.: High Altitude Drop Testing in Mars Relevant Conditions for the ARES Mars Scout Mission. AIAA 2003-6609, 2003. 


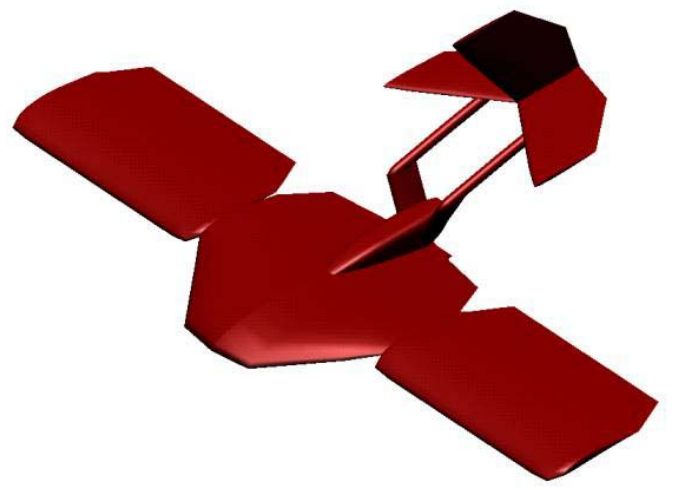

Figure 1. Example MAP airplane concept.
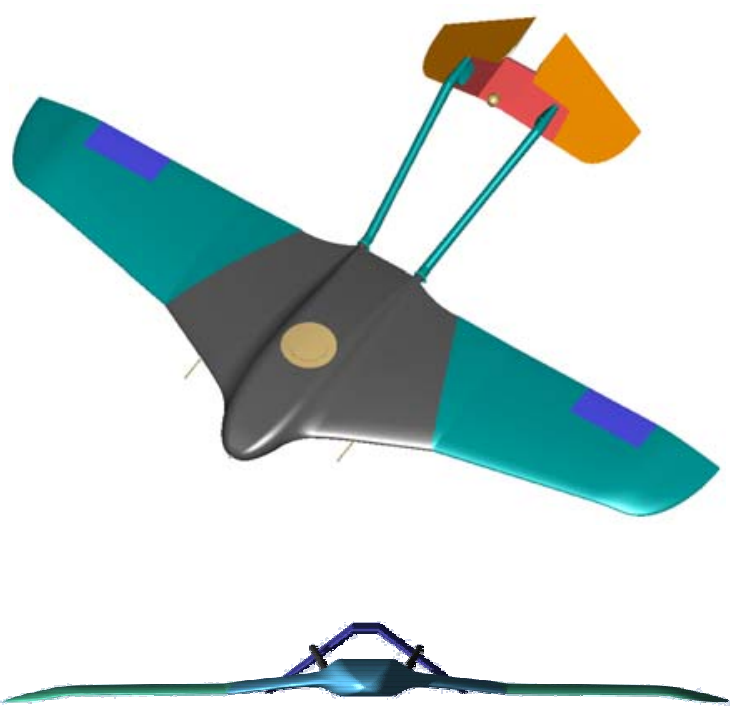

Figure 2. Current ARES airplane configuration, ARES-2.

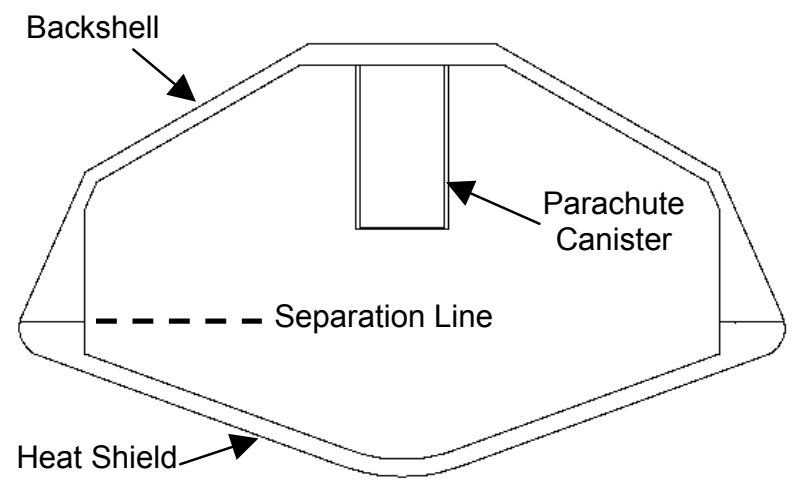

Figure 3. ARES aeroshell shape, Viking derivative with stretched backshell.

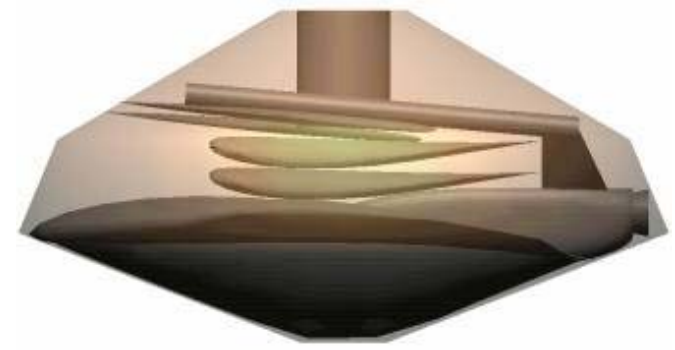

Figure 4. MAP overlapping wing folding scheme.

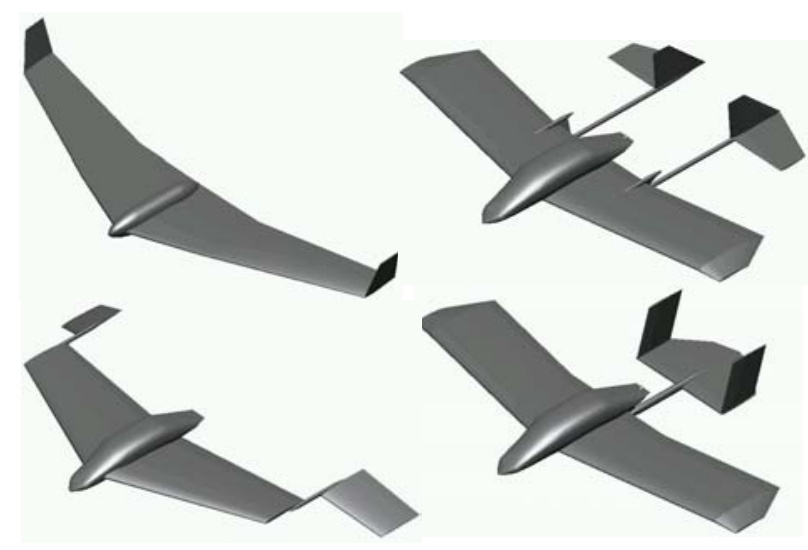

Figure 5. Some candidate ARES airplane configurations.

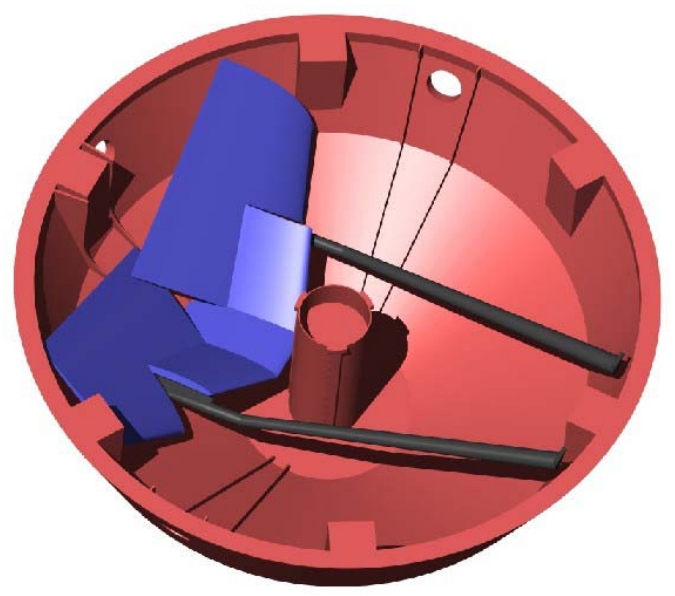

Figure 6. V-tail packaged in aeroshell backshell. 


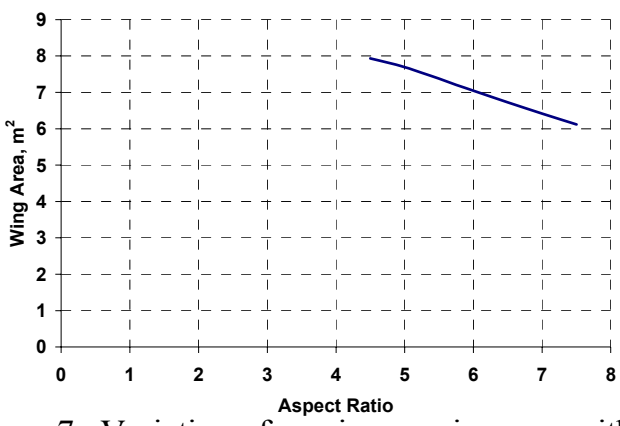

Figure 7. Variation of maximum wing area with aspect ratio.

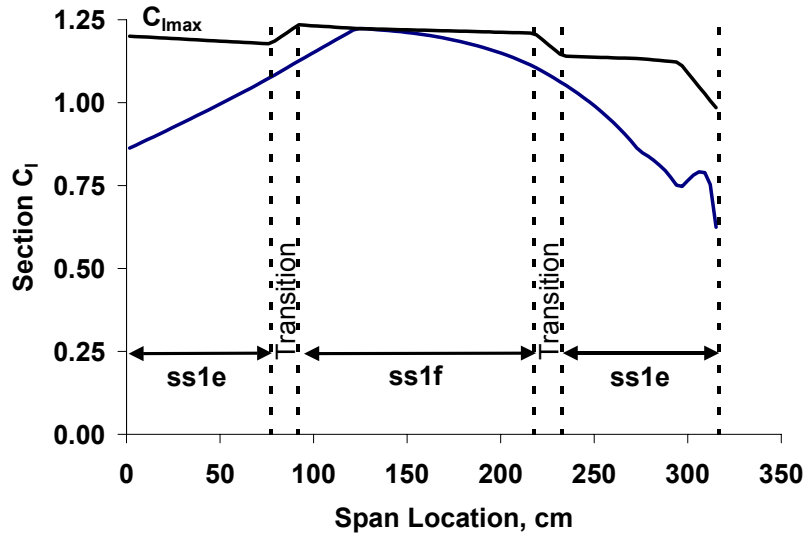

Figure 8. ARES-1 airfoil and lift coefficient distribution.

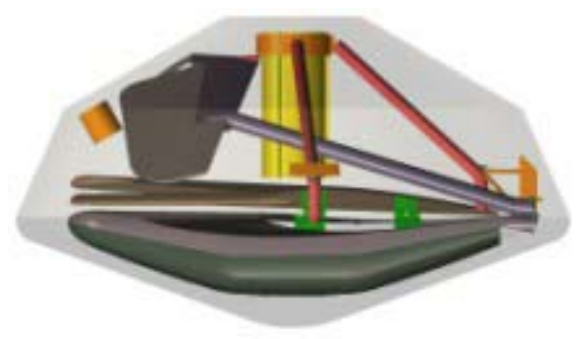

a.) Stowed in aeroshell.

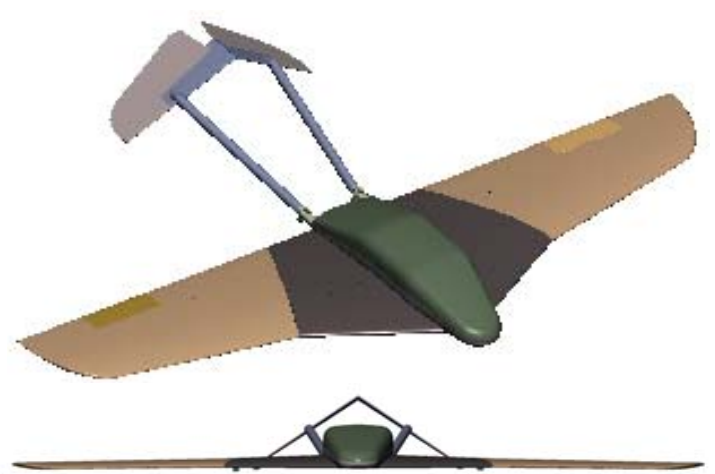

b.) Unfolded.

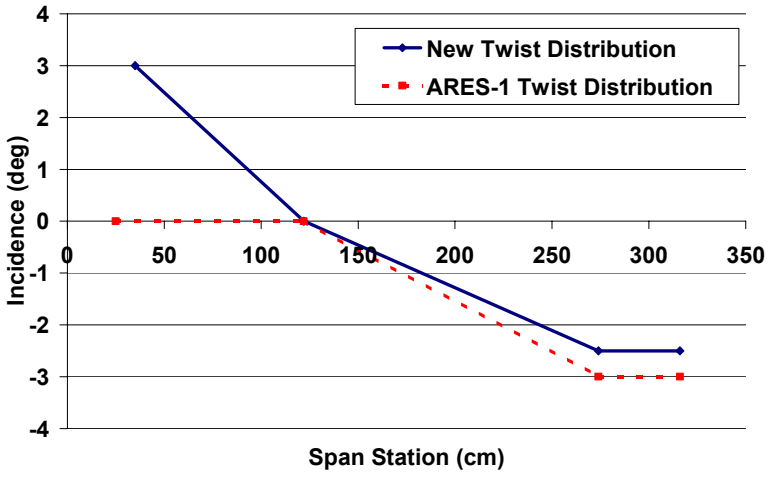

Figure 10. Comparison of airfoil twist distributions.

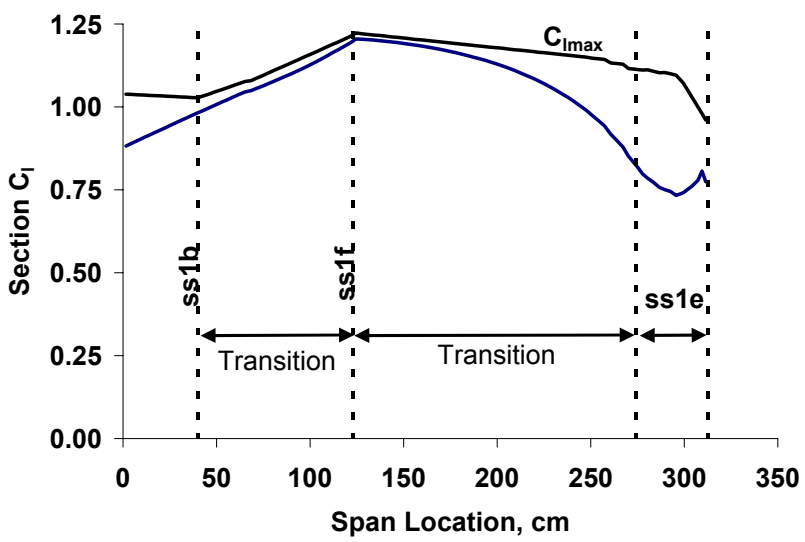

Figure 11. ARES-2 airfoil and lift coefficient distribution.

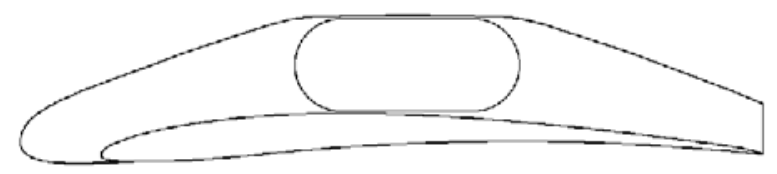

a.) ARES-1 fuselage.

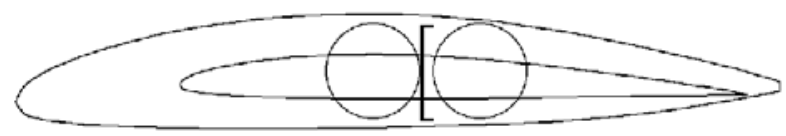

b.) ARES-2 fuselage.

Figure 12. Comparison of fuselage profiles.

Figure 9. ARES-1 configuration.

15

American Institute of Aeronautics and Astronautics 

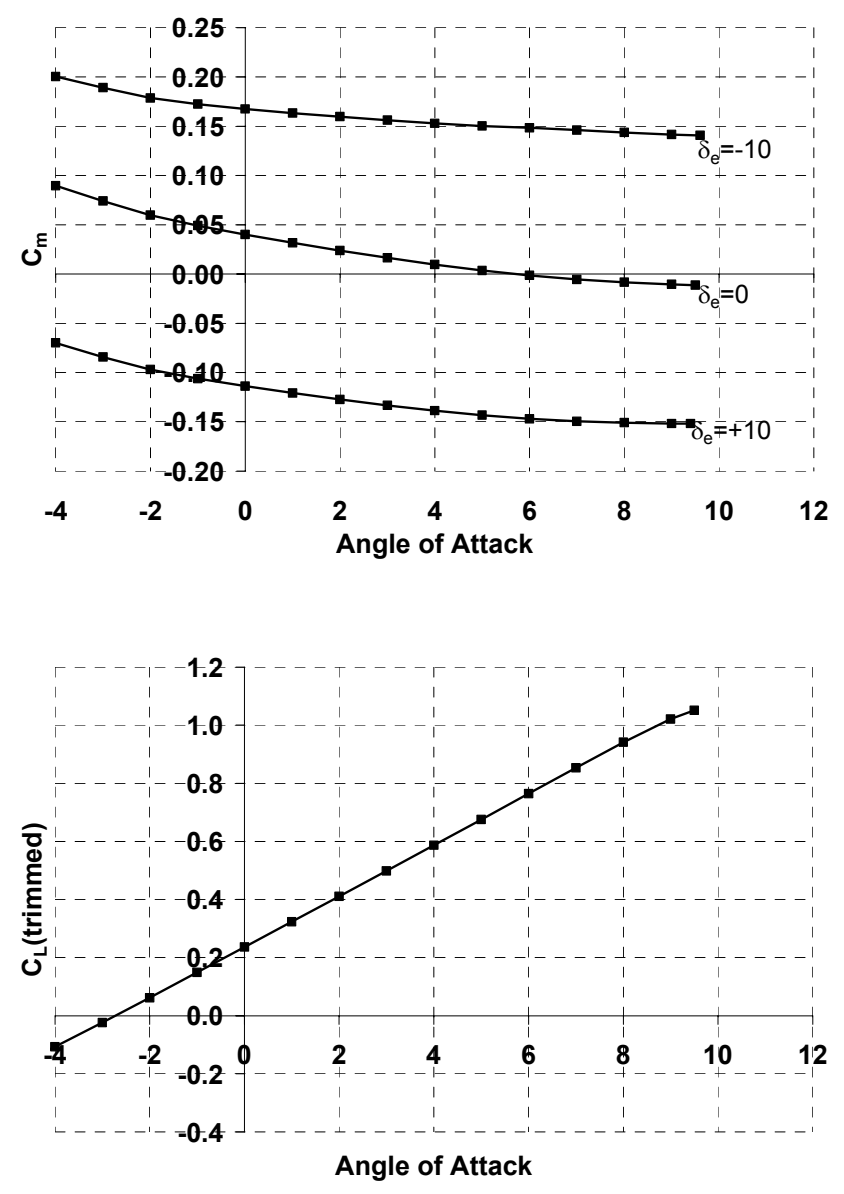

Figure 13. $\mathrm{C}_{\mathrm{m}}$ and trimmed $\mathrm{C}_{\mathrm{L}}$ characteristics. $\left(\mathrm{M}=0.65 ; \mathrm{Re}=200,000\right.$ per meter, $\left.\delta_{\text {flap }}=0\right)$

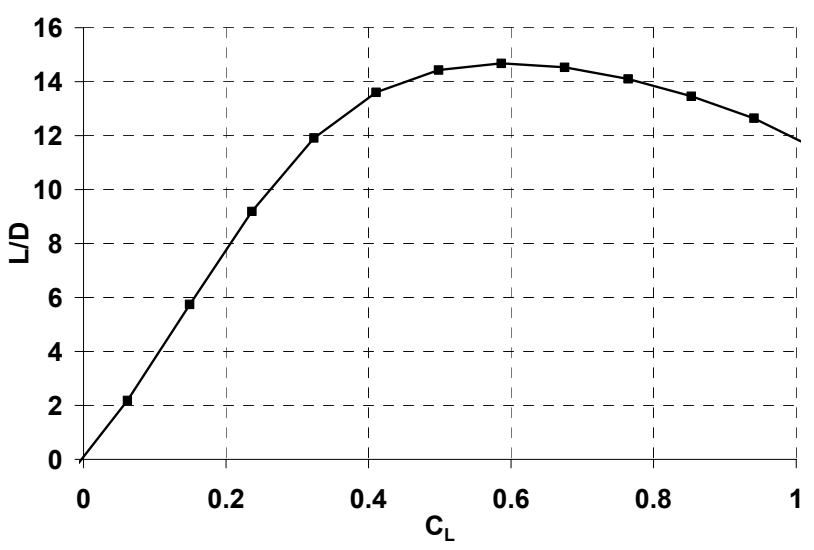

Figure 14. Lift-to-Drag ratio. $(\mathrm{M}=0.65 ; \mathrm{Re}=200,000$ per meter $)$

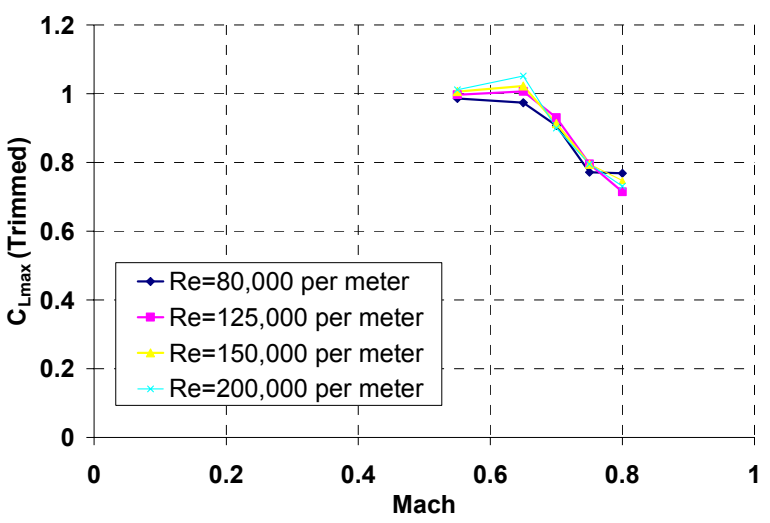

Figure 15. Mach and Reynolds number effects on $\mathrm{C}_{\text {Lmax }}$.

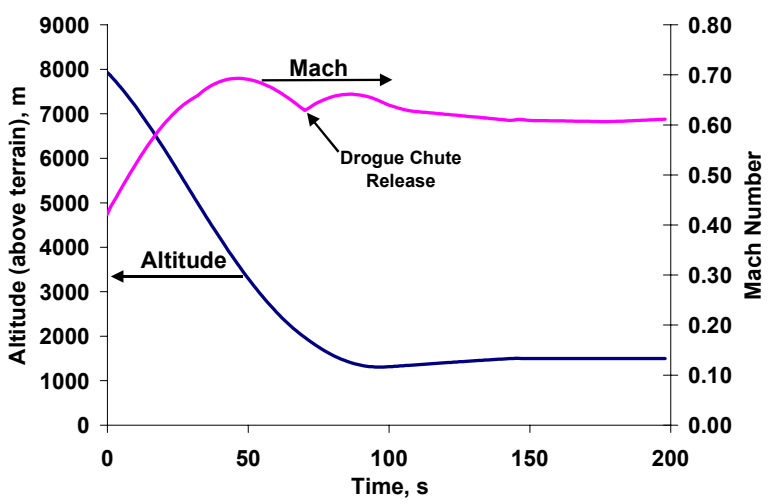

Figure 16. Nominal pullout performance for $175 \mathrm{~kg}$ airplane.

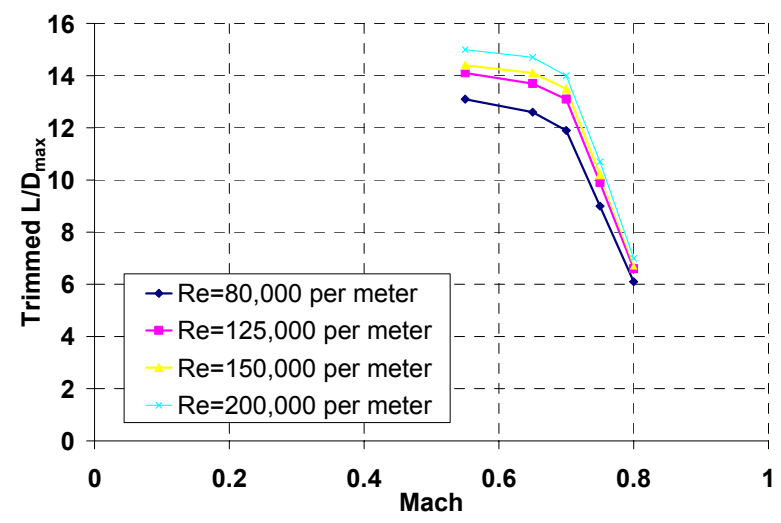

Figure 17. Mach and Reynolds number effects on L/D.

16

American Institute of Aeronautics and Astronautics 